Research Article

\title{
A Designer's Approach for Estimation of Nuclear-Air-Blast-Induced Ground Motion
}

\author{
Shashank Pathak iD and G. V. Ramana \\ Department of Civil Engineering, Indian Institute of Technology Delhi, New Delhi, India \\ Correspondence should be addressed to Shashank Pathak; shashankpathaks@gmail.com
}

Received 19 August 2017; Accepted 5 December 2017; Published 8 March 2018

Academic Editor: Chiara Bedon

Copyright (c) 2018 Shashank Pathak and G. V. Ramana. This is an open access article distributed under the Creative Commons Attribution License, which permits unrestricted use, distribution, and reproduction in any medium, provided the original work is properly cited.

\begin{abstract}
A reliable estimate of free-field ground displacement induced by nuclear-air-blast is required for design of underground strategic structures. A generalized pseudostatic formulation is proposed to estimate nuclear-air-blast-induced ground displacement that takes into account nonlinear stress-strain behaviour of geomaterials, stress-dependent wave propagation velocity, and stress wave attenuation. This proposed formulation is utilized to develop a closed-form solution for linearly decaying blast load applied on a layered ground medium with bilinear hysteretic behaviour. Parametric studies of closed-form solution indicated that selection of appropriate constrained modulus consistent with the overpressure is necessary for an accurate estimation of peak ground displacement. Stress wave attenuation affects the computed displacement under low overpressure, and stress-dependent wave velocity affects mainly the occurrence time of peak displacement and not its magnitude. Further, peak displacements are estimated using the proposed model as well as the UFC manual and compared against the field data of atmospheric nuclear test carried out at Nevada test site. It is found that the proposed model is in good agreement with field data, whereas the UFC manual significantly underestimates the peak ground displacements under higher overpressures.
\end{abstract}

\section{Introduction}

Underground siting of strategic structures [1] is an option to enhance the safety against nuclear-air-blast [2]. Nuclear explosions generate rapidly moving air-overpressures capable of producing significant ground displacements [3]. Most severe loading occurs within a close vicinity around the ground zero (GZ) known as superseismic zone. This zone is subjected to significantly high overpressures. The velocity of moving airoverpressure fronts is also more than the P-wave velocity of the ground [3-6]. Hence, a reliable estimate of nuclear-airblast-induced ground displacement is required for design in superseismic zone $[5,7,8]$. Several studies using numerical approaches that account for realistic stress-strain behaviour and boundary conditions are reported for calculating the freefield response [9-16]. Such studies require specialized expertise in numerical tools and are unattractive to practicing engineers. Before the advent of computational tools, Wilson and Sibley [17] conceptualized a one-dimensional pseudostatic approach to estimate air-blast-induced ground displacement.
Whitman [4] and Baron et al. [18] have also shown that air-blast-induced ground motion is predominantly one-dimensional and vertical in superseismic zone. In the present work, a generalized one-dimensional pseudostatic formulation is developed to estimate nuclear-air-blast-induced vertical ground displacement that accounts for (i) nonlinear stress-strain behaviour [e.g., 19, 20], (ii) stress-dependent wave propagation velocity, and (iii) stress wave attenuation. Using the proposed formulation, a closed-form solution is developed for linearly decaying blast load with negligible rise-time applied on a layered ground medium with bilinear hysteretic stress-strain behaviour. The proposed model is validated against the field data of an atmospheric nuclear test conducted at Nevada test site [21], and various parametric studies are carried out. In addition, performance of the closed-form solution is also compared with the model given in UFC [22].

\section{Generalized Formulation}

The developed formulation is explained in detail below. 
2.1. Determination of Overstress Distribution (due to AirBlast) in the Ground. Air-overpressure generated due to nuclear-air-blast consists of an initial rising portion followed by a decaying portion (Figure 1). Overpressure time-history can be visualized as consisting of multiple overpressure fronts. These overpressure fronts are transferred to the ground as P-waves. On arrival of an air-shock front at the point of interest, an initial pulse travels with seismic P-wave velocity and reaches a depth $Z_{0 i}$ at time $t_{i}$. Subsequently, other fronts arrive and penetrate into the ground. If the location of peak overpressure front at time $t_{i}$ is given as $Z_{p i}$, then, the ground above the depth $Z_{p i}$ experiences compressive stresses lower than those caused by the peak overpressure front at that depth. Therefore, the depths above $Z_{p i}$ are referred to as "unloading zone." However, the peak overpressure front is yet to reach at locations deeper than $Z_{p i}$, and therefore, the zone lying beneath the depth $Z_{p i}$ is denoted as "loading zone" (Figure 1). It is noted that "unloading zone" corresponds to the "decay portion" of overpressure, whereas "loading zone" corresponds to the "rising portion." Therefore, at times earlier than the rise-time, there does not exist any unloading zone as overpressure fronts from the decay portion do not arrive before the end of rise-time.

To determine the stress distribution in the ground at time $t_{i}$, contribution from all stress fronts arrived before time $t_{i}$ is considered. If the $k$ th overpressure front arrives at the point of interest on ground surface at time $t_{k}$ such that $t_{k} \leq t_{i}$, then the $k$ th overpressure front reaches at depth $Z_{k i}$ at time $t_{i}$. Stress fronts propagating through ground are affected by attenuation (caused by hysteresis losses, viscosity of ground materials, and dispersion of energy in 3-dimensional space) and interference with reflected wave fronts (generated due to impedance variation with depth). In the present study, stress wave attenuation is taken into account through a geometrical attenuation parameter, whereas interference of incident and reflected stress waves is ignored. If the attenuation coefficient at depth $Z_{k i}$ is given as
$\alpha\left(Z_{k i}\right)$, then the stress generated at depth $Z_{k i}$ can be written as $\alpha\left(Z_{k i}\right) \times P\left(t_{k}\right)$, where $P\left(t_{k}\right)$ is the magnitude of the $k$ th overpressure front. Depth of the penetration $Z_{k i}$ depends upon wave propagation velocity of the stress front, which in turn depends upon the tangential modulus of the geomaterial at the stress level at the depth of interest. If wave velocity of the $k$ th stress front is denoted as $V_{k z}$ (a function of depth " $z$ "), then (1) can be solved to obtain $Z_{k i}$ as a function of $t_{i}, t_{k}$, and $V_{k z}(2)$,

$$
\begin{aligned}
\int_{0}^{Z_{k i}} \frac{\mathrm{dz}}{V_{k z}} & =t_{i}-t_{k}, \\
Z_{k i} & =g\left(t_{i}-t_{k}, V_{k z}\right)=\varphi\left(t_{k}\right),
\end{aligned}
$$

where $g$ is the function obtained by solving (1). It is noted that for a given $t_{i}, Z_{k i}$ is effectively a function $(\varphi)$ of $t_{k}$ only because $V_{k z}$ is also a function of $t_{k}$. As soon as the air-blast slaps the ground surface, ground deforms elastically and an elastic wave is generated which propagates with seismic P-wave velocity. Upon subsequent arrival of higher overpressure fronts, inelastic waves propagate at velocities smaller than $\mathrm{P}$-wave velocity. If the ratio of $\mathrm{P}$-wave velocity to wave velocity corresponding to the $k$ th overpressure front at depth " $z$ " is denoted as $f_{k z}=\left(V_{p z} / V_{k z}\right)$, then at initial stress levels $f_{k z}$ is equal to one. With increasing stress level, $V_{k z}$ decreases $[17,23]$; hence, it is logical to assume that $f_{k z}$ increases with increasing stress level and the maximum value is attained at a peak stress level corresponding to the peak overpressure front. Therefore, a simplest choice is to assume a linearly increasing $f_{k z}$ in direct proportion to overpressure (3). Overpressure fronts from the decay portion propagate through the media which is already stressed in a nonlinear range due to passage of the peak overpressure front. Therefore, it is assumed that wave velocity of overpressure fronts in the decay portion is the same as the peak overpressure front, and hence $f_{k z}$ is the same as $f_{r z}$ :

$$
f_{k z}= \begin{cases}\left(f_{r z}-1\right) \frac{P\left(t_{k}\right)}{P_{\mathrm{o}}}+1 \approx\left(f_{r z}-1\right) \frac{t_{k}}{t_{r}}+1, & 0 \leq t_{k} \leq t_{r}: \text { rising portion } \\ f_{r z}, & t_{r} \leq t_{k} \leq t_{p}: \text { decay portion }\end{cases}
$$

where subscript " $z$ " represents the depth coordinate. Using the average loading rate as $P_{\mathrm{o}} / t_{r}, P\left(t_{k}\right) / P_{\mathrm{o}}$ can be approximated as $t_{k} / t_{r}$ (3). As wave propagation velocity through ground media is proportional to the square root of the tangential modulus [24], $f_{r z}$ is given by the following equation:

$$
f_{r z}=\sqrt{\frac{\left.\left(\partial \sigma_{z} / \partial \varepsilon_{z}\right)\right|_{\sigma=0}}{\left.\left(\partial \sigma_{z} / \partial \varepsilon_{z}\right)\right|_{\sigma_{r z}}}}
$$

where $\left.\left(\partial \sigma_{z} / \partial \varepsilon_{z}\right)\right|_{\sigma=0}$ is the tangential modulus at initial stress level at depth " $z$ " and $\left.\left(\partial \sigma_{z} / \partial \varepsilon_{z}\right)\right|_{\sigma_{r z}}$ is the tangential modulus at peak stress level at depth " $z$."
It should be noted that the ground is in equilibrium under geostatic stresses and at rest before nuclear explosion and only the overstresses caused by nuclear-air-blast causes the ground displacement.

2.2. Determination of Strain Distribution in Ground. Strain distribution with depth $\left(\varepsilon_{i z}\right)$ can be determined using stress distribution $\left(\sigma_{i z}\right)$ and an appropriate stress-strain relationship [e.g., 25-27] as given in the following equation:

$$
\varepsilon_{i Z}=\left\{\begin{array}{l}
f_{L}\left(z, \sigma_{i z}\right): \text { loading } \\
f_{U}\left(z, \sigma_{i z}\right): \text { unloading, }
\end{array}\right.
$$




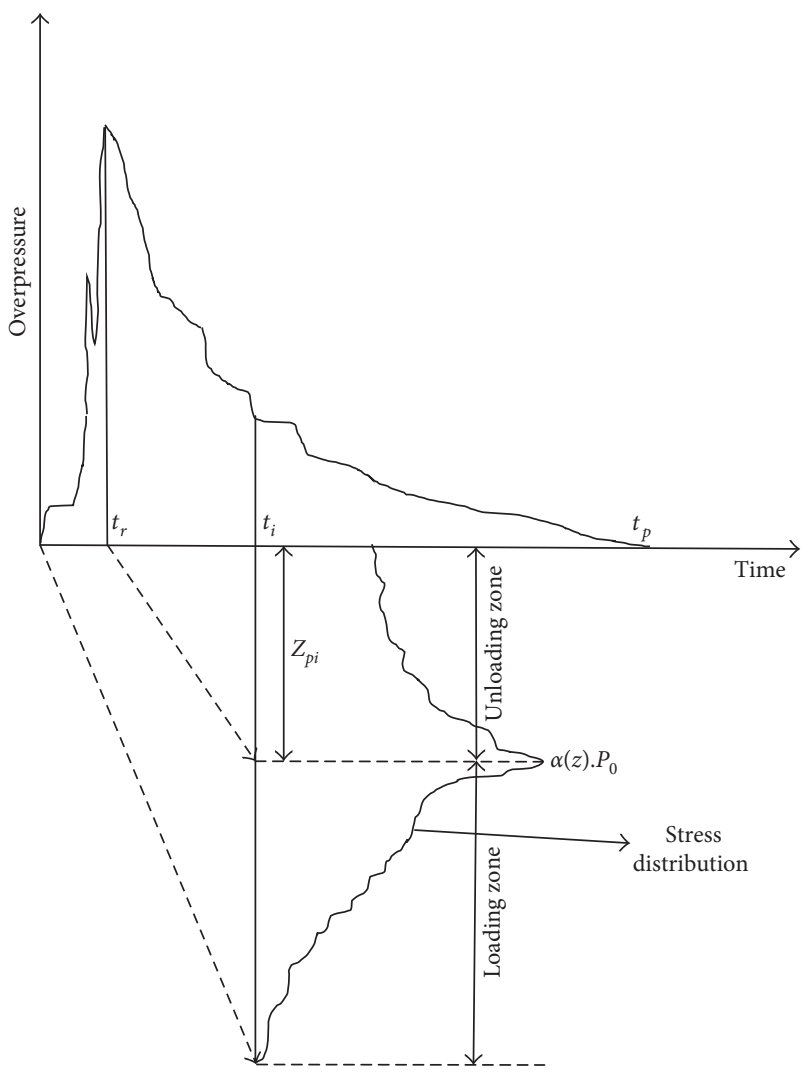

FIgURE 1: Schematic representation of dilatational stress distribution in ground at time $t_{i}$.

where functions $f_{L}$ and $f_{U}$ denote the loading and unloading branches of the stress-strain curve, respectively (Figure 2).

2.3. Integration of Strains. To obtain the vertical ground displacement $u_{i}$ at time instant $t_{i}$, the strain distribution is

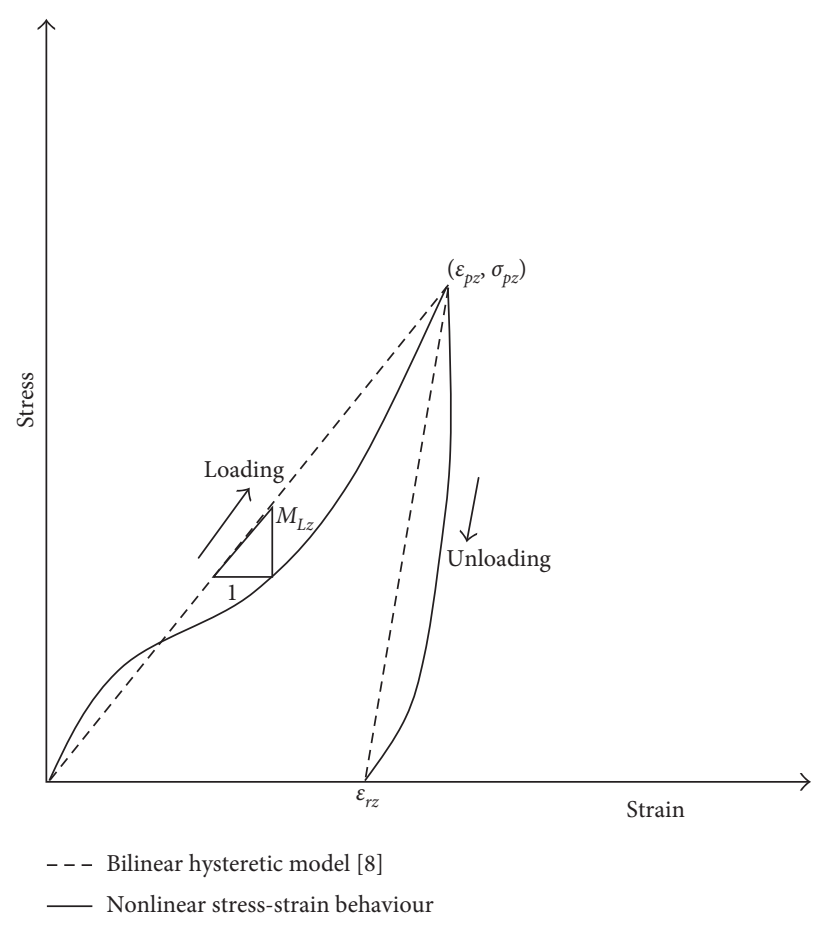

FIgURE 2: Schematic diagram for stress-strain relation at a depth " $z$."

integrated (6) from the ground surface to the penetrated wavelength in the ground up to time $t_{i}\left(Z_{0 i}\right)$,

$$
u_{i}=\int_{0}^{Z_{0 i}} \varepsilon_{i z} \mathrm{dz}=\int_{0}^{Z_{r i}} f_{U}(z, \sigma) \mathrm{d} z+\int_{Z_{r i}}^{Z_{0 i}} f_{L}(z, \sigma) \mathrm{d} z
$$

Substituting $Z=\varphi\left(t_{k}\right)$ in (6) leads to the following equation:

$$
u_{i}= \begin{cases}\int_{t_{i}}^{0} f_{L}\left(\varphi\left(t_{k}\right), \sigma\left(\varphi\left(t_{k}\right)\right)\right) \times \varphi^{\prime}\left(t_{k}\right) \mathrm{dt}_{k}, & 0 \leq t_{i} \leq t_{r}: \text { loading } \\ \int_{t_{r}}^{0} f_{L}\left(\varphi\left(t_{k}\right), \sigma\left(\varphi\left(t_{k}\right)\right)\right) \times \varphi^{\prime}\left(t_{k}\right) \mathrm{dt}_{k}+\int_{t_{i}}^{t_{r}} f_{U}\left(\varphi\left(t_{k}\right), \sigma\left(\varphi\left(t_{k}\right)\right)\right) \times \varphi^{\prime}\left(t_{k}\right) \mathrm{dt}_{k}, & t_{r} \leq t_{i} \leq t_{p}: \text { unloading. }\end{cases}
$$

Thus, the displacement time-history can be estimated using (7).

\section{Closed-Form Solution}

Using (7), closed-form solutions can be obtained for several simplified cases [28]. In this article, a closed-form approximation is developed for the following simplifications:

(a) Linearly decaying overpressure time-history with zero rise-time (Figure 3, (8)),

$$
P\left(t_{k}\right)=P_{\mathrm{o}}\left(1-\frac{t_{k}}{t_{\mathrm{eq}}}\right)
$$

where $P_{\mathrm{o}}$ and $t_{\mathrm{eq}}$ are peak overpressure and equivalent positive phase duration, respectively.
The reason behind choosing the special case with zero rise-time is the popularity of approximating the actual decay of the incidental pressure by an equivalent triangular pressure pulse among practicing engineers $[8,22]$. It is to mention that design charts and empirical relations between the weapon yield, peak overpressure, and the equivalent positive phase durations are also available for equivalent triangular pulses with zero risetime $[5,8,29]$. Thus, for practicing engineers, a linear decay model with zero rise-time is more useful.

(b) Bilinear hysteretic stress-strain model [8] with the loading secant modulus $\left(M_{L}\right)$ and strain recovery ratio $(r)$ as parameters (Figure 2). 


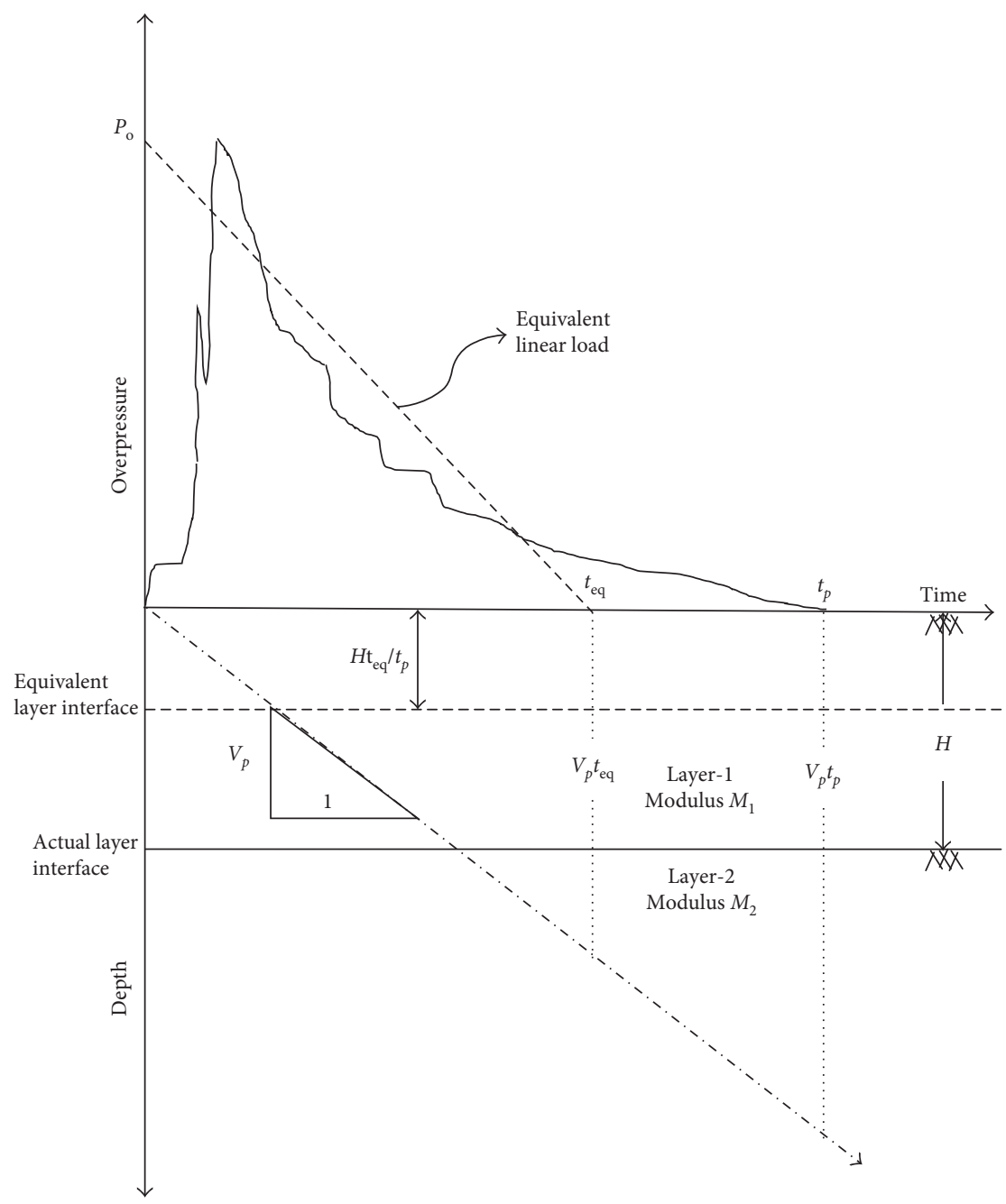

Figure 3: Scaling of equivalent ground media.

(c) Attenuation coefficient $(\alpha)$ is given by the following equation $[8,30]$ :

$$
\alpha=\left(1+\frac{z}{L_{w}}\right)^{-1},
$$

where $L_{w}=0.971 \times W^{1 / 3} \times P_{\mathrm{o}}^{-1 / 2} \times V_{L}$, where $W$ is the yield of the explosion in kiloton and $V_{L}$ is the wave propagation velocity of the peak overpressure front.

(d) Using (4), $f_{r z}$ is determined as 1 for the bilinear stress-strain model. However, due to nonlinear stress- strain behaviour, $f_{r z}$ is usually greater than 1 . Wilson and Sibley [17] and Batdorf [23] recommended a range of 1.5 to 2 . Hereafter, $f_{r z}$ is denoted as $f$ and assumed to be constant with depth.

(e) A constant but representative $\mathrm{P}$-wave velocity $V_{p}$ of ground media is assumed.

Using assumptions (a)-(e), integral for loading fronts in (7) (with $t_{r} \rightarrow 0$ ) between general time instants $t_{x}$ and $t_{x+1}$ is written as $\operatorname{Lim}_{t_{r} \rightarrow 0}\left[\int_{t_{x}}^{t_{x+1}} f_{L}\left(\varphi\left(t_{k}\right), \sigma\left(\varphi\left(t_{k}\right)\right)\right) \times \varphi^{\prime}\left(t_{k}\right) \mathrm{dt}_{k}\right]=$ $P_{\mathrm{o}} / M_{L} \times \operatorname{Lim}_{t_{r} \rightarrow 0} L\left(t_{x} \rightarrow t_{x+1}\right)$, where $L\left(t_{x} \rightarrow t_{x+1}\right)$ can be shown to be given by the following equation:

$$
\begin{aligned}
L\left(t_{x} \longrightarrow t_{x+1}\right)= & \frac{(f-1) t_{i}+t_{r}}{(f-1) L_{w}-t_{r} V_{p}} \times\left[\frac{L_{w} V_{p}}{(f-1)} \ln \left(\frac{(f-1) t_{x+1}+t_{r}}{(f-1) t_{x}+t_{r}}\right)+\frac{L_{w}\left(L_{w}+V_{p} t_{i}\right)}{\left(t_{r}+f t_{i}-t_{i}\right)}\right. \\
& \left.\times \ln \left(\frac{\left(f L_{w}-L_{w}-t_{r} V_{p}\right) t_{x+1}+t_{r}\left(L_{w}+V_{p} t_{i}\right)}{\left(f L_{w}-L_{w}-t_{r} V_{p}\right) t_{x}+t_{r}\left(L_{w}+V_{p} t_{i}\right)} \times \frac{(f-1) t_{x}+t_{r}}{(f-1) t_{x+1}+t_{r}}\right)\right] .
\end{aligned}
$$




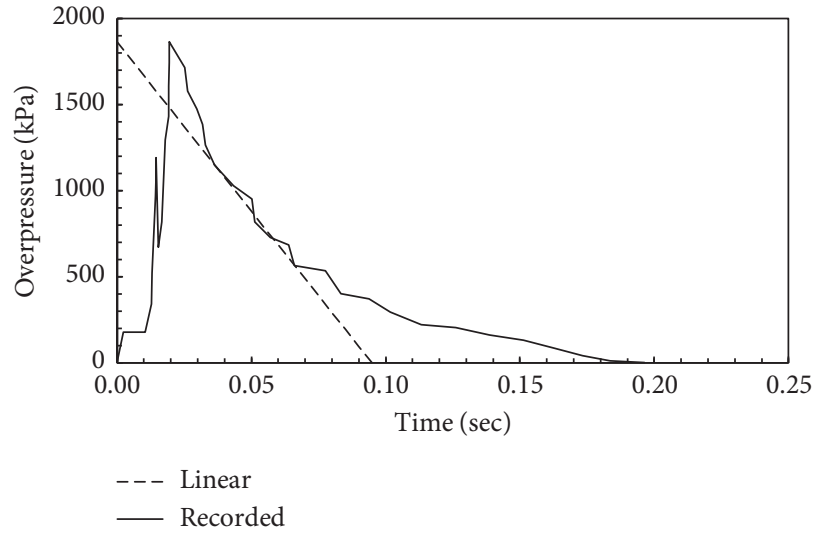

(a)

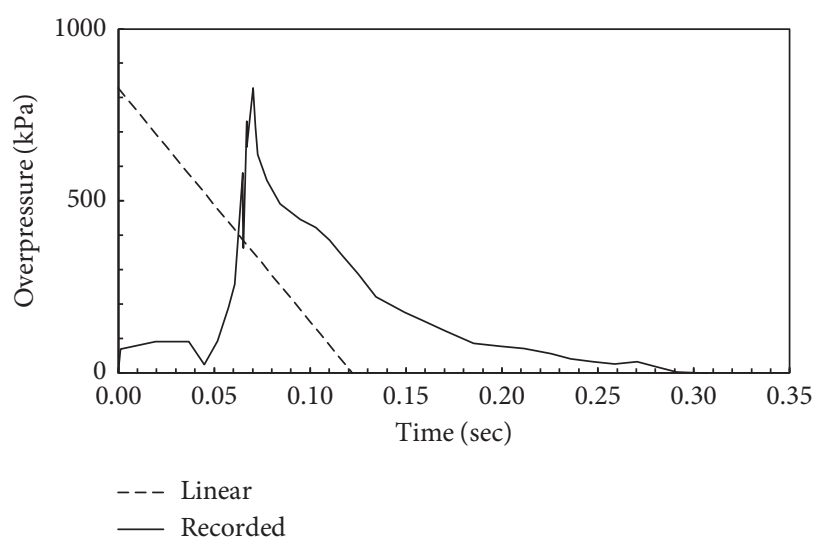

(c)

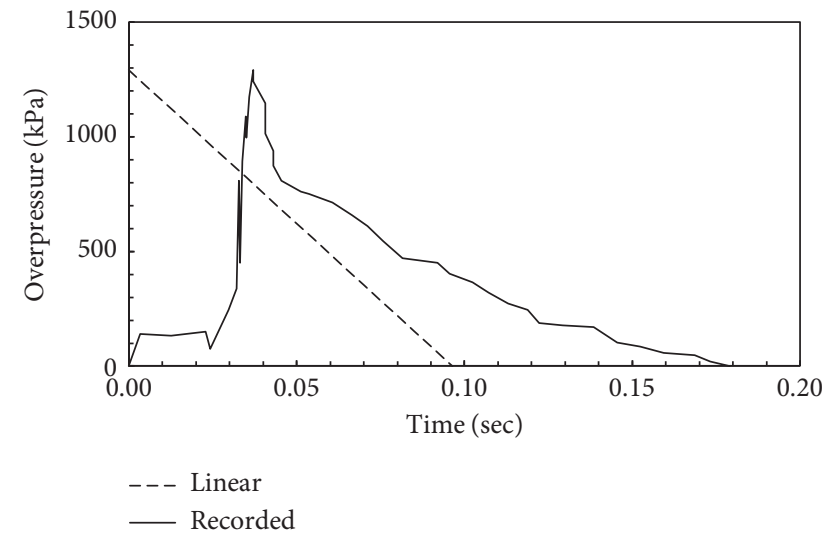

(b)

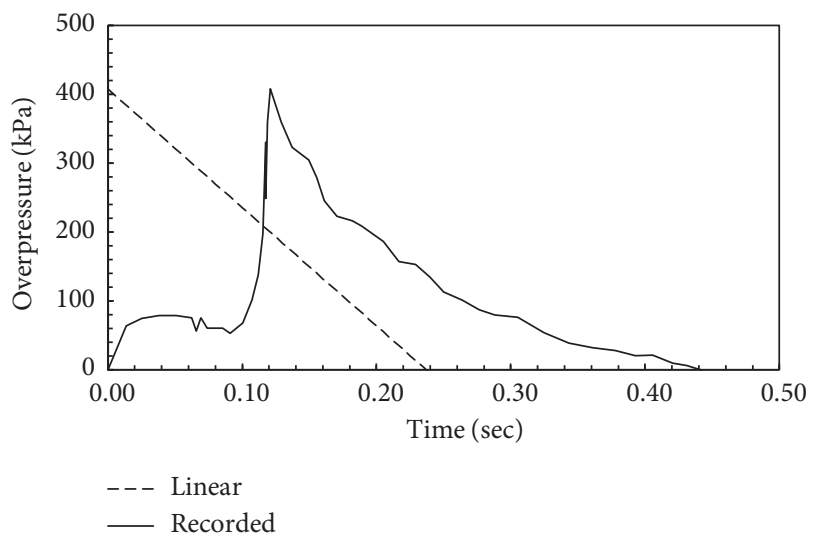

(d)

Figure 4: Measured and equivalent (linear) overpressure time-histories for shot Priscilla at stations (a) P1, (b) P2, (c) P3, and (d) P4 (measured overpressure time-histories [21]).

It is to clarify that the overpressure time-history defined by the piecewise function $P\left(t_{k}\right)$ such that $P\left(t_{k}\right)=P_{0} t_{k} / t_{r}$ for $t_{k} \leq t_{r}$ and $P\left(t_{k}\right)=P_{\mathrm{o}}\left(1-\left(t_{k}-t_{r}\right)\right) /\left(t_{\mathrm{eq}}-t_{r}\right)$ for $t_{r} \leq t_{k} \leq t_{\mathrm{eq}}$ converges to (8) in the limiting case when $t_{r} \rightarrow 0$. Therefore, the expression $L\left(t_{x} \rightarrow t_{x+1}\right)$ in (10) is first obtained for a case of finite $t_{r}$ and then it is evaluated for the case when $t_{r} \rightarrow 0$ to determine the solution for overpressure time-history of (8). Similarly, the integral for unloading fronts in (7) (with $t_{r} \rightarrow 0$ ) between general time instants $t_{x}$ and $t_{x+1}$ can be written as $\int_{t_{x+1}}^{t_{x}} f_{U}\left(\varphi\left(t_{k}\right), \sigma\left(\varphi\left(t_{k}\right)\right)\right) \times \varphi^{\prime}\left(t_{k}\right) \mathrm{dt}_{k}=\left(P_{0} / M_{L}\right) \times$ $U\left(t_{x} \rightarrow t_{x+1}\right)$, where $U\left(t_{x} \rightarrow t_{x+1}\right)$ can be shown to be given by the following equation:

$$
\begin{aligned}
U\left(t_{x} \longrightarrow t_{x+1}\right)= & L_{w}\left[1-\frac{r f L_{w}}{t_{p} V_{p}}-\frac{r t_{i}}{t_{p}}\right] \ln \left(\frac{f L_{w}+V_{p} t_{i}-V_{p} t_{x}}{f L_{w}+V_{p} t_{i}-V_{p} t_{x+1}}\right) \\
& +\frac{r L_{w}\left(t_{x+1}-t_{x}\right)}{t_{p}} .
\end{aligned}
$$

By setting the appropriate values of $t_{x}$ and $t_{x+1}$ in (10) and (11), the closed-form integrals between desired time instants can easily be evaluated. Thus, the closed-form solution is given by the following equation:

$$
u_{i}=\frac{P_{\mathrm{o}}}{M_{L}} \operatorname{Lim}_{t_{r} \rightarrow 0}\left[L\left(0 \longrightarrow t_{r}\right)+U\left(t_{r} \longrightarrow t_{i}\right)\right]
$$

The closed-form solution is further extended to accommodate multiple ground layers. This requires the determination of time instants $t_{x}$ and $t_{x+1}$ during which the wave fronts pass through a particular layer. For illustration, a layered ground medium with an interface at depth $H$ with the modulus of top layer as $M_{1}$ and modulus of bottom layer as $M_{2}$ is considered as shown in Figure 3. This leads to the three cases (Table 1) and corresponding displacement solutions (shown in Table 1).

\section{Validation}

The proposed closed-form solution is validated against the field data from an atmospheric nuclear test conducted at Frenchman Flat (Nevada). Perret [21] presented the measured overpressure time-histories (Figure 4) along with corresponding peak ground displacements at different distances from GZ (Table 2) for a $37 \mathrm{kt}$ nuclear explosion at 

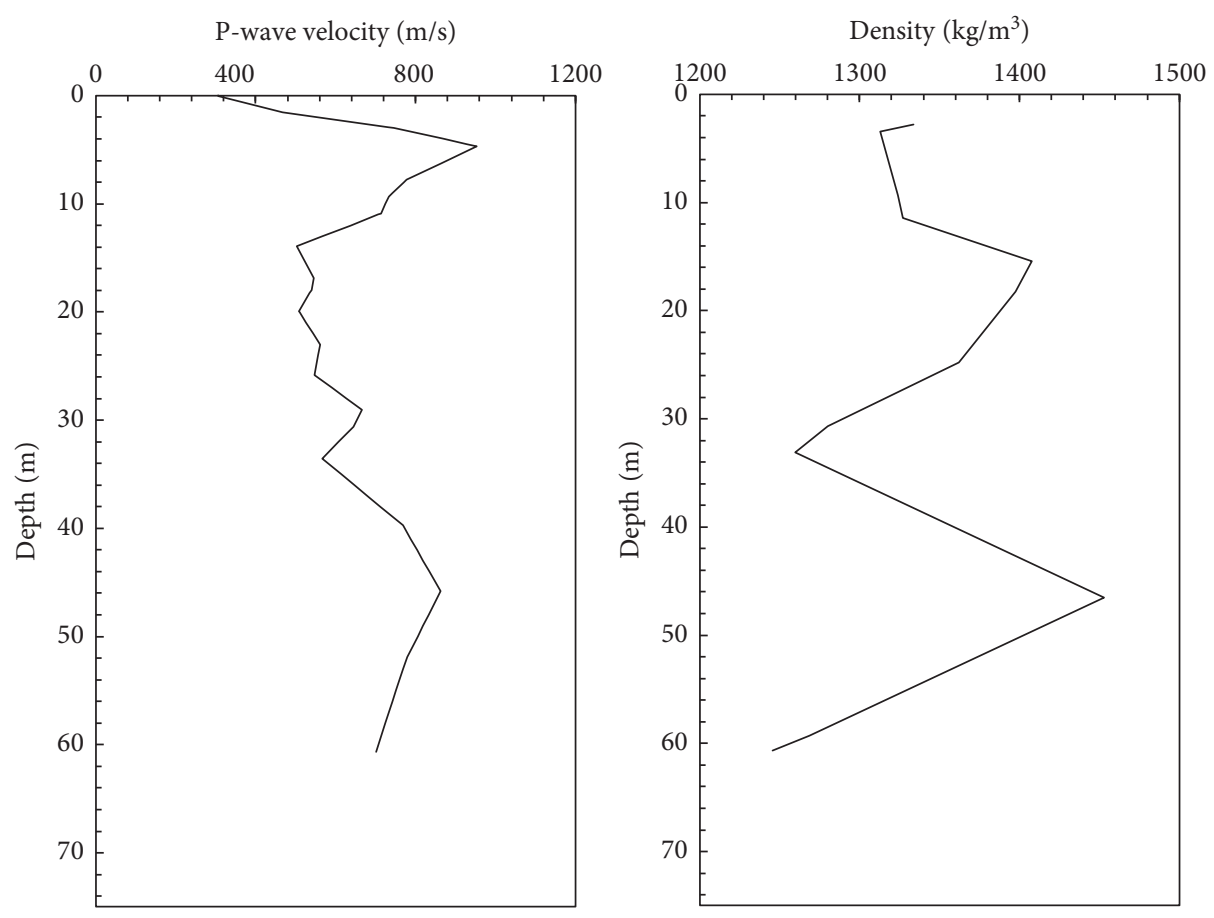

FIGURE 5: P-wave velocity and geomaterial density profile at Frenchman Flat, NTS [21].

a height of $214 \mathrm{~m}$. Model input parameters for above mentioned nuclear test are determined as follows.

The recorded overpressure time-histories are converted to equivalent linearly decaying overpressure time-histories (Figure 4). Equivalent overpressure timehistories are given by (8) such that the peak overpressure $\left(P_{\mathrm{o}}\right)$ is equal to the recorded peak overpressure, and equivalent positive phase duration $t_{\mathrm{eq}}$ is given by the following equation:

$$
t_{\mathrm{eq}}=\frac{2 I_{p}}{P_{\mathrm{o}}},
$$

where $I_{p}$ is the positive phase impulse (area under the recorded overpressure time-history). It is worth mentioning, though the rise-time is taken to be zero in the equivalent overpressure time-history in (8), that the effect of non-zero rising time has been accounted for by considering the total positive phase impulse (in (13)) which includes the area under the rising and decaying portions of actual overpressure time-history. Therefore, it is expected that setting the rise-time as zero in (8) would have a negligible impact on the magnitude of peak displacement. Furthermore, the ratios of length of rise-time to total positive phase duration for the four cases (P1, P2, P3, and $\mathrm{P} 4$ ) are $0.10,0.21,0.23$, and 0.27 , respectively. This indicates that rise-time is reasonably small near ground zero; however, the relative length of rise-time increases with increasing distance from ground zero. Thus, it is expected that the errors (if any) due to setting rise-time to zero would be more pronounced only at distances far away from ground zero. Even in such cases, a closed-form solution can be developed using (7) by setting a finite risetime. However, it is worth noting that at far away distances (from ground zero), other important factors related to outrunning ground motion would start governing [31].

The initial pulse moving at seismic $\mathrm{P}$-wave velocity $\left(V_{p}\right)$ penetrates to a depth of $V_{p} t_{\text {eq }}$ for equivalent case, whereas for actual case, it penetrates to a depth of $V_{p} t_{p}$. It is noted that the depth of the stressed zone in the equivalent case is smaller compared to the actual case as equivalent duration $\left(t_{\text {eq }}\right)$ is smaller than the actual positive phase duration $\left(t_{p}\right)$ (Figure 4). Thus, all depth-dependent parameters are scaled by a factor $\mathrm{SF}=t_{p} / t_{\mathrm{eq}}$, such that the total depth of the stressed zone becomes $\mathrm{SF} \times V_{p} t_{\mathrm{eq}}=V_{p} t_{p}$ with the depth of the top layer being $H / S F$, and with a characteristic attenuation length of $L_{w} / \mathrm{SF}$. Based on the variation of P-wave velocity with depth at Frenchman Flat (Figure 5), the average P-wave velocity $\left(V_{p}\right)$ is estimated as $658.69 \mathrm{~m} / \mathrm{s}$. Whitman [4] presented the representative constrained modulus for Frenchman Flat interpreted from different experimental techniques (Table 3). Whitman [4] also emphasized that all aspects of stress-strain behaviour of geomaterials under blast loading are not captured by a single test and advocated to choose the modulus judiciously. The stress attenuation coefficient is calculated using (9) with scaled $L_{w}$ (Table 4). Using the closed-form solution (shown in Table 1), parametric variations are studied (Table 5) and peak displacements (Table 6) are estimated.

The parametric studies (Table 5) highlight that the proposed model is most sensitive to the constrained modulus compared to other parameters and choice of the modulus is also subjective for engineers. However, based on the parametric studies, the last column "Recommended Value" of Table 5 provides some guidelines to select the constrained modulus. With increasing 


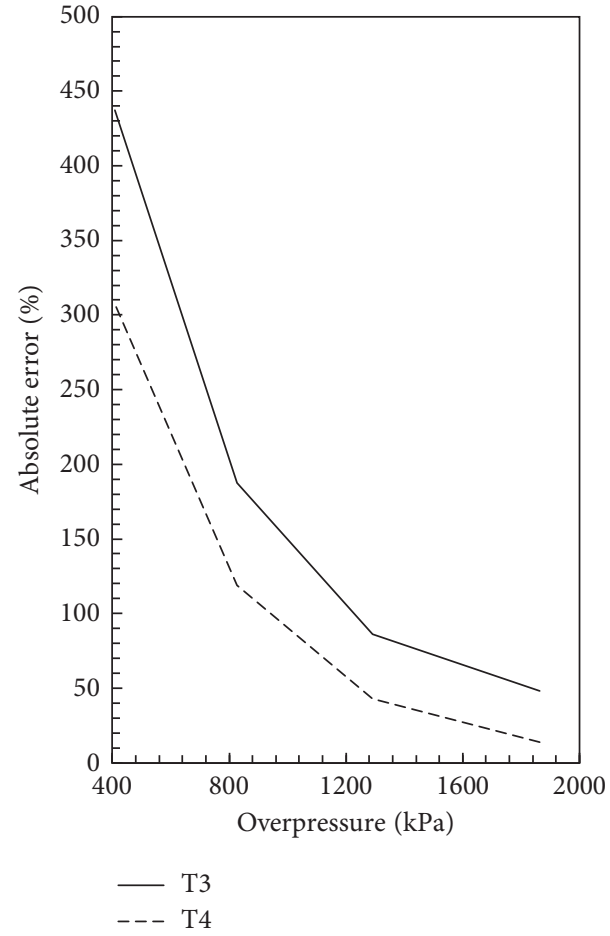

(a)

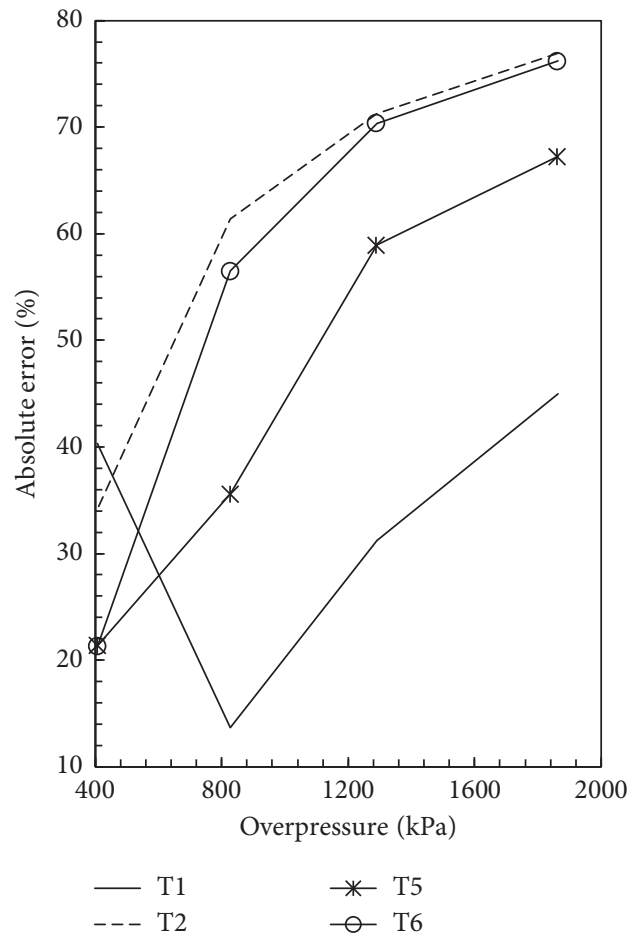

(b)

FIGURE 6: Variation of error in estimated peak displacement using constrained modulus determined from different experimental techniques: (a) T3 and T4 and (b) T1, T2, T5, and T6. T1: deduced from observed ground motion; T2: calculated from seismic velocity; T3: triaxial tests: initial loading; T4: dynamic 1-D compression test: initial loading; T5: triaxial tests: reloading; T6: resonant column test.

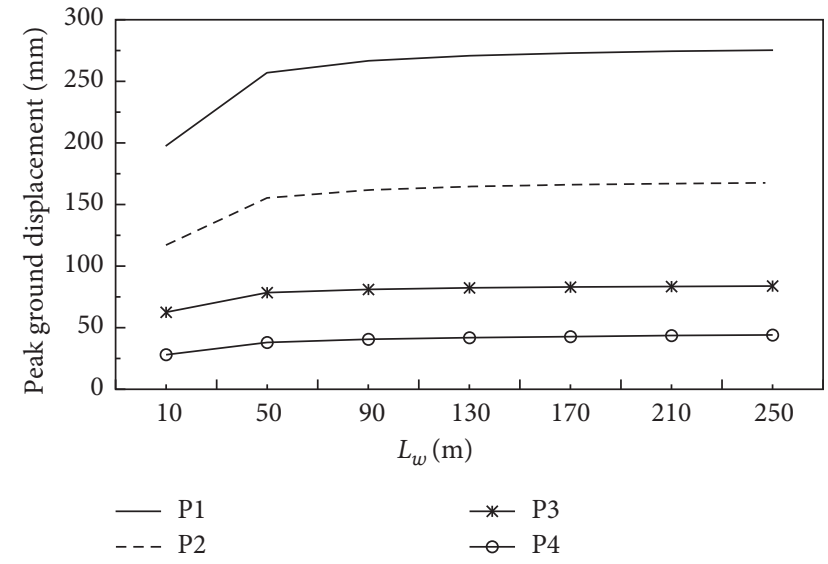

FIGURE 7: Variation of peak ground displacement with attenuation characteristic length $L_{w}$.

availability of similar case studies, these guidelines can further be refined.

\section{Comparison with UFC Model}

The UFC manual [22] provides an expression for air-blastinduced peak vertical displacement based on one-dimensional elastic wave propagation:

$$
\left.u_{i}\right|_{\max }=\frac{I_{p}}{\rho V_{p}},
$$

where $\rho$ is the bulk density of geomaterials. To estimate peak displacements using (14), positive phase impulse $\left(I_{p}\right)$ is taken from Table 2. Representative P-wave velocity $\left(V_{p}\right)$ and density $(\rho)$ are taken as $658.69 \mathrm{~m} / \mathrm{s}$ and $1331 \mathrm{~kg} / \mathrm{m}^{3}$, respectively, taking into account the variation with depth (Figure 5). Computed peak displacements using the proposed model and UFC model are shown in Figure 9 along with the measured field values. It can be clearly seen that the predicted values of the proposed model are in good agreement with the measured values and the UFC model significantly underestimates the peak displacements under high overpressures (with increasing war head capacity).

\section{Conclusions}

A closed-form expression is developed to estimate nuclearair-blast-induced free-field ground displacement that takes into account peak overpressure, positive phase impulse, depth of layer interface, representative constrained modulus of each layer, strain recovery, stress attenuation, P-wave velocity, and velocity ratio. The solution is validated against a nuclear test conducted at Frenchman Flat (Nevada) and the following conclusions are arrived at:

(i) Peak ground displacement estimates are quite sensitive to the constrained modulus, and a judicious 

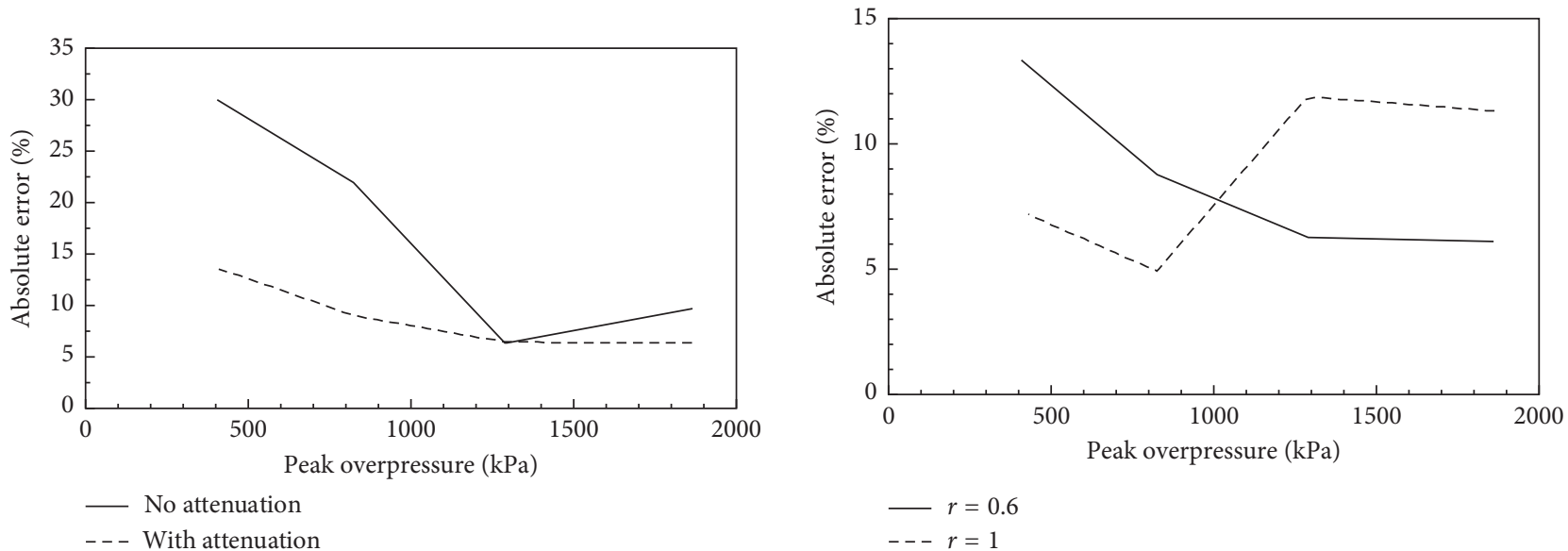

(a)

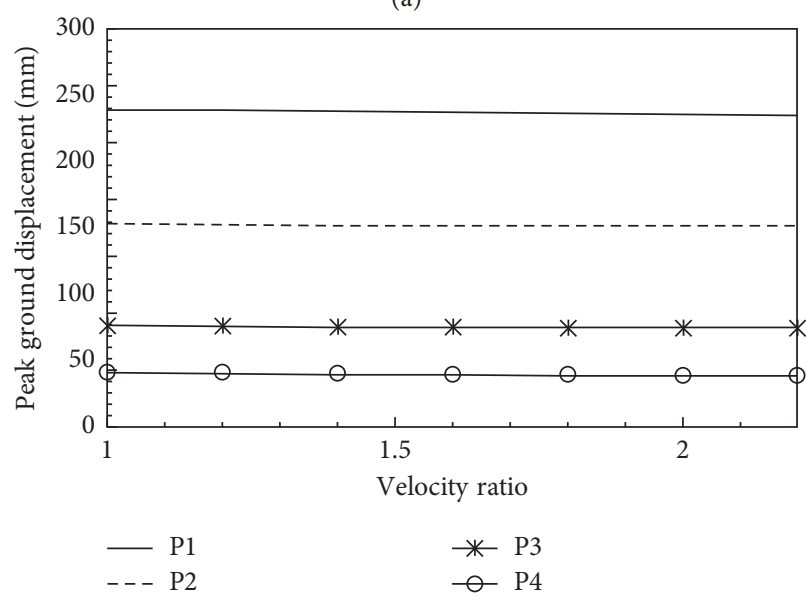

(c)

(b)

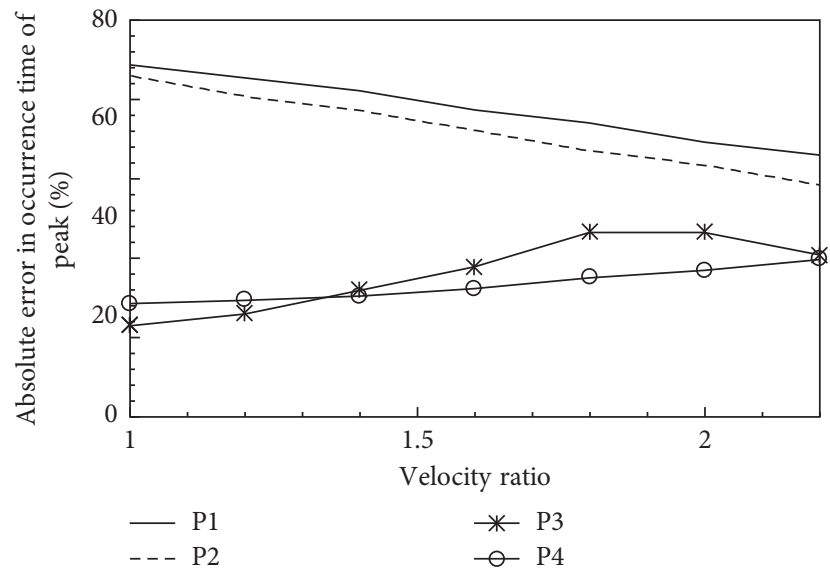

(d)

FIGURE 8: Effect of (a) attenuation; (b) strain recovery ratio; (c) velocity ratio on estimated ground displacement; (d) velocity ratio on time of occurrence of peak displacement.

selection of appropriate constrained modulus based on the magnitude of applied overpressure is recommended.

(ii) Based on the presented case study, two guidelines are recommended to select the appropriate modulus: (a) shallow ground layers are likely to have modulus values determined by unconfined or triaxial compression test and deep ground layers are likely to have modulus values computed from seismic velocity test, and (b) constrained modulus increases with decreasing ratio of applied stress to overburden.

(iii) Effect of attenuation should be accounted for low overpressures and may be neglected at higher overpressures (or high war head capacities).

(iv) The velocity ratio affects mainly the time of occurrence of peak ground displacement and not the

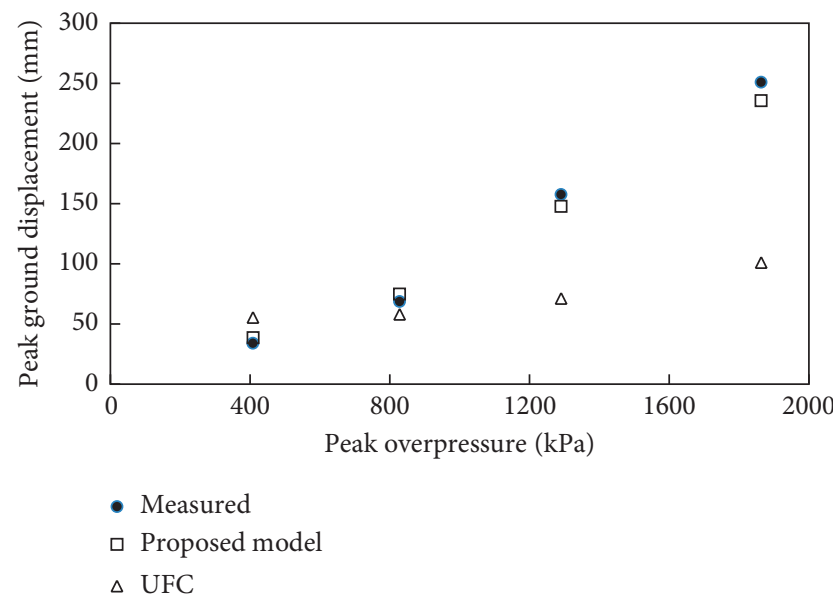

FIgURE 9: Comparison between measured and estimated peak ground displacements. 
TABLE 1: Displacement solutions for the double-layered media.

\begin{tabular}{|c|c|c|}
\hline Case & Explanation & Displacement equation \\
\hline 1 & $\begin{array}{l}\text { When all loading and unloading fronts are in layer-1 } \\
\qquad\left(t_{i} \leq H / V_{p}\right) .\end{array}$ & $u_{i}=P_{o} \operatorname{Lim}_{t_{r} \rightarrow 0}\left[\frac{L\left(0 \rightarrow t_{r}\right)}{M_{1}}+\frac{U\left(t_{r} \rightarrow t_{i}\right)}{M_{1}}\right]$ \\
\hline 2 & $\begin{array}{l}\text { When some loading fronts have crossed layer- } 1 \text { and } \\
\text { remaining loading fronts along with all unloading } \\
\text { fronts are in layer- } 1\left(H / V_{p}<t_{i} \leq f H / V_{p}\right) \text {. Here, the } \\
\text { first task is to determine those loading fronts which } \\
\text { have crossed layer-1. This can be obtained by equating } \\
\text { loading front velocity multiplied with travel time with } \\
\text { the depth of layer. The loading front velocity of the } \\
k \text { th front can be written using (3) as } \\
V_{p} /\left\{(f-1)\left(t_{k} / t_{r}\right)+1\right\} \text {, and travel time is }\left(t_{i}-t_{k}\right) \text {. } \\
\text { Thus, the last loading front to reach at depth } H \text { by the } \\
\text { time } t_{i} \text { would be given by } \\
\qquad t_{k H}=t_{r}\left(V_{p} t_{i}-H\right) /\left\{H(f-1)+V_{p} t_{r}\right\} .\end{array}$ & $u_{i}=P_{o} \operatorname{Lim}_{t_{r} \rightarrow 0}\left[\frac{L\left(0 \rightarrow t_{k H}\right)}{M_{2}}+\frac{L\left(t_{k H} \rightarrow t_{r}\right)}{M_{1}}+\frac{U\left(t_{r} \rightarrow t_{i}\right)}{M_{1}}\right]$ \\
\hline 3 & $\begin{array}{l}\text { When all loading fronts are in layer- } 2 \text { and some } \\
\text { unloading fronts have crossed layer- } 1\left(f H / V_{p}<t_{i}\right) \text {. } \\
\text { Similar to case } 2 \text {, the last unloading front to reach at } \\
\text { depth } H \text { by the time } t_{i} \text { would be given by } \\
\qquad t_{k H}=t_{i}-f H / V_{p} .\end{array}$ & $u_{i}=P_{o} \operatorname{Lim}_{t_{r} \rightarrow 0}\left[\frac{L\left(0 \rightarrow t_{r}\right)}{M_{2}}+\frac{U\left(t_{r} \rightarrow t_{i}-f H / V_{p}\right)}{M_{2}}+\frac{U\left(t_{i}-f H / V_{p} \rightarrow t_{i}\right)}{M_{1}}\right]$ \\
\hline
\end{tabular}

TABLE 2: Details of recording stations.

\begin{tabular}{lcccccc}
\hline $\begin{array}{l}\text { Station } \\
\text { designation }\end{array}$ & $\begin{array}{c}\text { Range } \\
(\mathrm{m})\end{array}$ & $\begin{array}{c}\text { Peak overpressure } \\
(\mathrm{kPa})\end{array}$ & $\begin{array}{c}\text { Positive phase duration } \\
(\mathrm{sec})\end{array}$ & $\begin{array}{c}\text { Positive phase impulse } \\
(\mathrm{kPa}-\mathrm{sec})\end{array}$ & $\begin{array}{c}\text { Equivalent duration } \\
(\mathrm{sec})\end{array}$ & $\begin{array}{c}\text { Scale factor } \\
(\mathrm{SF})\end{array}$ \\
\hline P1 & 198 & 1863 & 0.196 & 88.32 & 62.18 & 0.0948 \\
P2 & 259 & 1290 & 0.179 & 50.54 & 0.0964 & 2.07 \\
P3 & 320 & 828 & 0.307 & 48.34 & 0.1221 & 0.2371 \\
P4 & 411 & 408 & 0.442 & & 2.51 & 1.86 \\
\hline
\end{tabular}

Table 3: Constrained modulus of playa silt at Frenchman Flat [4].

\begin{tabular}{lccc}
\hline Method & \multirow{2}{*}{ Notation } & \multicolumn{2}{c}{ Constrained modulus (MPa) } \\
& & For depths less than $18 \mathrm{~m}$ & For depths more than $18 \mathrm{~m}$ \\
\hline Deduced from observed ground motion & T1 & 242 & 552 \\
Calculated from seismic velocity & T2 & 55.6 & 1035 \\
Triaxial tests: initial loading & T3 & 69 & 103.5 \\
Dynamic 1-D compression test: initial loading & T4 & 276 & 138 \\
Triaxial tests: reloading & T5 & 276 & 448.5 \\
Resonant column test & T6 & 759 \\
\hline
\end{tabular}

TABLE 4: Scaling of attenuation characteristic length $\left(L_{w}\right)$.

\begin{tabular}{|c|c|c|c|c|c|}
\hline Station designation & $W(\mathrm{kt})$ & $P_{\mathrm{o}}(\mathrm{kPa})$ & $V_{p}(\mathrm{~m} / \mathrm{s})$ & $L_{w}(\mathrm{~m})$ & Scaled $L_{w}(\mathrm{~m})$ \\
\hline $\mathrm{P} 1$ & \multirow{4}{*}{37} & 1863 & 658.69 & 48.58 & 23.47 \\
\hline P2 & & 1290 & 658.69 & 58.38 & 31.44 \\
\hline P3 & & 828 & 658.69 & 72.88 & 28.98 \\
\hline $\mathrm{P} 4$ & & 408 & 658.69 & 103.84 & 55.70 \\
\hline
\end{tabular}

magnitude under higher overpressures. Therefore, the velocity ratio becomes important when design calculations utilize the complete displacement timehistory such as in case of shock spectra. (v) A complete strain recovery is a better representation of actual conditions under low overpressure zones, and under higher overpressures, a partial strain recovery is recommended. 
TABLE 5: Parametric studies carried out on the proposed closed-form solution.

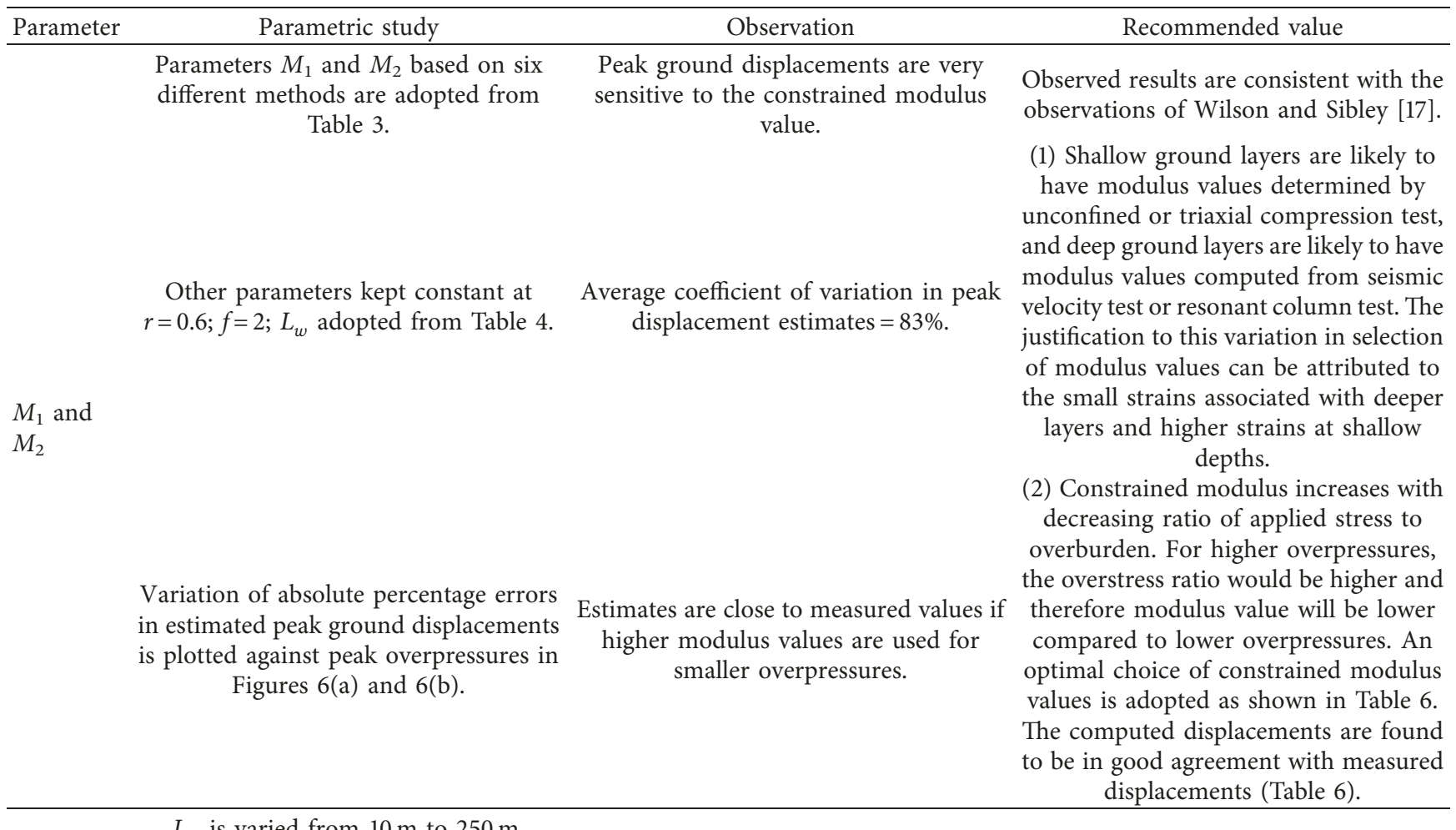

$L_{w}$ is varied from $10 \mathrm{~m}$ to $250 \mathrm{~m}$. Other parameters kept fixed at $M_{1}$ and $M_{2}$ adopted from Table $6 ; f=2 ; r=0.6$.

Estimated peak displacements are

$L_{w} \quad$ plotted against $L_{w}$ as shown in Figure 7. Errors in estimated peak displacements for the attenuating medium and nonattenuating medium are also plotted against peak overpressure in Figure 8(a).
As $L_{w}$ increases (or $\alpha$ decreases), peak displacement increases.

Beyond $L_{w}$ of $250 \mathrm{~m}$, the peak ground displacement does not increase, and

$L_{w} \geq 250$ is considered as the non-attenuating medium.
Attenuation has to be taken into account under low overpressures, and it can be ignored under high overpressures.
Two cases are considered: (i) full strain recovery $r=1$ and (ii) partial strain recovery $r=0.6$.

Other parameters fixed at $M_{1}$ and $M_{2}$ Assumption of full strain recovery gives adopted from Table $6 ; f=2 ; L_{w}$ adopted from Table 4 .

Errors in estimated peak displacement for the two cases are plotted as shown in Figure 8(b). less errors as compared to partial strain recovery under low overpressures.
Under low overpressure, ground is not stressed beyond its elastic limit, and hence full strain recovery is a better representation of actual conditions in low overpressure zones.

A lower strain recovery causes higher permanent deformations and increases peak ground displacement compared to elastic case (i.e., unit strain recovery ratio). Under higher overpressures, the ground is stressed beyond its elastic limit and the assumption of partial strain recovery is recommended.

\section{$f$ is varied from 1.0 to 2.2 .}

Other parameters fixed at $M_{1}$ and $M_{2}$ adopted from Table 6; $r=0.6 ; L_{w}$ adopted from Table 4.

Estimated peak displacements are plotted against $f$ (Figure $8(\mathrm{c})$ ).

Error in occurrence time of peak displacement are also plotted against $f$
Under high overpressure (P1 and P2), error in occurrence time of peak displacement reduces significantly with increasing $f$.

Error increases marginally under lower overpressures as the velocity ratio is close to 1 under lower stress (in (3) when $\left.t_{k} \rightarrow 0\right)$. $f$ has insignificant effect on magnitude of estimated peak displacements. However, as the velocity ratio increases, the risetime of overstress pulse with depth also increases and affects the occurrence time of the peak displacement. 
TABLE 6: Suggested combination of modulus values and corresponding estimated peak displacements.

\begin{tabular}{|c|c|c|c|c|c|}
\hline $\begin{array}{l}\text { Station } \\
\text { designation }\end{array}$ & $\begin{array}{c}M_{1}(\mathrm{MPa}) \\
\text { (depths less than } 18 \mathrm{~m} \text { ) }\end{array}$ & $\begin{array}{c}M_{2}(\mathrm{MPa}) \\
\text { (depths more than } 18 \mathrm{~m} \text { ) }\end{array}$ & $\begin{array}{c}\text { Estimated peak } \\
\text { displacement }(\mathrm{mm})\end{array}$ & $\begin{array}{l}\text { Experimental } \\
\text { records }(\mathrm{mm})\end{array}$ & $\begin{array}{c}\% \\
\text { error } \\
\end{array}$ \\
\hline $\mathrm{P} 1$ & $\begin{array}{c}55.2 \\
\text { triaxial tests: initial loading }\end{array}$ & $\begin{array}{c}552 \\
\text { deduced from observed } \\
\text { ground motion }\end{array}$ & 235.59 & 250.95 & 6.12 \\
\hline P2 & $\begin{array}{c}69 \\
\text { dynamic } 1-\mathrm{D} \text { compression } \\
\text { test: initial loading }\end{array}$ & $\begin{array}{l}759 \\
\text { resonant column test }\end{array}$ & 147.68 & 157.56 & 6.27 \\
\hline P3 & $\begin{array}{c}69 \\
\text { dynamic } 1-\mathrm{D} \text { compression } \\
\text { test: initial loading }\end{array}$ & $\begin{array}{l}759 \\
\text { resonant column test }\end{array}$ & 74.79 & 68.75 & 8.79 \\
\hline $\mathrm{P} 4$ & $\begin{array}{l}96.6 \\
\text { deduced from observed } \\
\text { ground motion }\end{array}$ & $\begin{array}{l}1035 \\
\text { calculated from } \\
\text { seismic velocity }\end{array}$ & 38.49 & 33.95 & 13.37 \\
\hline
\end{tabular}

(vi) The proposed model closely estimates the experimental values at all overpressures, whereas the UFC model significantly underestimates the peak ground displacements at high overpressures.

\section{Notations}

$\alpha\left(Z_{k i}\right)$
$\varepsilon_{i z}:$
$\varepsilon_{p z}:$
$\varepsilon_{r z}:$
$f:$

$f_{k z}$ :

$f_{L}$ :

$f_{r z}$ :

$f_{U}:$

$H:$

$I_{p}$ :

$L_{w}$ :

$M_{L}$ :

$M_{2}$ :

$M_{1}$ :

$P_{\mathrm{o}}$ :

$P\left(t_{k}\right)$ :

$r:$

$\rho:$

SF:

$\sigma_{p z}$ :

$t_{\text {eq }}$ :

$t_{k}:$
Attenuation coefficient at depth $Z_{k i}$

Strain at time $t_{i}$ at depth " $z$ "

Peak strain level in geomaterial at depth " $z$ " Residual strain level in geomaterial at depth " $z$ " Representative velocity ratio (between P-wave velocity and peak stress velocity) of ground media

Ratio of P-wave velocity to wave velocity corresponding to the $k$ th overpressure front at depth " $z$ "

Functional form for the loading branch of the stress-strain curve

Ratio of P-wave velocity to wave velocity corresponding to the peak overpressure front at depth " $z$ "

Functional form for the unloading branch of the stress-strain curve

Depth of the top ground layer

Positive phase impulse of overpressure timehistory

Characteristic attenuation length

Loading secant modulus

Modulus of bottom layer

Modulus of top layer

Peak overpressure

Pressure magnitude of the $k$ th overpressure front

Strain recovery ratio

Bulk-density of geomaterials

Scale factor

Peak stress level in geomaterial at depth " $z$ " Equivalent positive phase duration of linearly decaying overpressure time-history Time when the $k$ th overpressure front arrives at the point of interest on ground surface

\begin{tabular}{|c|c|}
\hline$t_{k H}:$ & $\begin{array}{l}\text { Time of arrival of the last loading front to } \\
\text { reach at depth } H \text { (by the time } t_{i} \text { ) }\end{array}$ \\
\hline$t_{p}:$ & $\begin{array}{l}\text { Positive phase duration of overpressure } \\
\text { time-history }\end{array}$ \\
\hline$t_{r}:$ & $\begin{array}{l}\text { Rise-time to peak overpressure in } \\
\text { overpressure time-history }\end{array}$ \\
\hline$u_{i}:$ & Vertical ground displacement at time $t_{i}$ \\
\hline$V_{p}:$ & $\begin{array}{l}\text { Representative P-wave velocity of ground } \\
\text { media }\end{array}$ \\
\hline$V_{L}:$ & $\begin{array}{l}\text { Representative wave propagation velocity of } \\
\text { the peak overpressure front in ground }\end{array}$ \\
\hline$V_{k z}:$ & $\begin{array}{l}\text { Wave velocity of the } k \text { th stress front at depth } \\
\text { " } z \text { " }\end{array}$ \\
\hline$W:$ & Yield of the explosion \\
\hline$Z_{k i}:$ & $\begin{array}{l}\text { Depth penetrated by the } k \text { th overpressure } \\
\text { front at time } t_{i}\end{array}$ \\
\hline$\sigma_{i z}:$ & Stress at time $t_{i}$ at depth " $z$ " \\
\hline$Z_{0 i}:$ & Depth penetrated by initial pulse at time $t_{i}$ \\
\hline$Z_{p i}:$ & $\begin{array}{l}\text { Depth penetrated by the peak overpressure } \\
\text { front at time } t_{i}\end{array}$ \\
\hline$\left.\left(\partial \sigma_{z} / \partial \varepsilon_{z}\right)\right|_{\sigma=0}:$ & $\begin{array}{l}\text { Tangential modulus at initial stress level at } \\
\text { depth " } z \text { " }\end{array}$ \\
\hline$\left.\left(\partial \sigma_{z} / \partial \varepsilon_{z}\right)\right|_{\sigma_{r z}}:$ & $\begin{array}{l}\text { Tangential modulus at peak stress level at } \\
\text { depth " } z \text {." }\end{array}$ \\
\hline
\end{tabular}

\section{Conflicts of Interest}

The authors declare that there are no conflicts of interest regarding the publication of this paper.

\section{References}

[1] S. Pinto, "Underground construction of nuclear power reactors," Nuclear Engineering and Design, vol. 61, no. 3, pp. 441-458, 1980.

[2] C. V. Chester and G. P. Zimmerman, "Civil defense shelters: a state-of-the-art assessment," Tunnelling and Underground Space Technology, vol. 2, no. 4, pp. 401-428, 1987.

[3] S. Glasstone and P. J. Dolan, The Effects of Nuclear Weapons, Castle House Publications, London, UK, 1980.

[4] R. V. Whitman, The Response of Soils to Dynamic Loadings; Report 26, Final Report, Massachusetts Institute of Technology, Cambridge, MA, USA, 1970. 
[5] R. E. Crawford, C. J. Higgins, and E. H. Bultmann, The Air Force Manual for Design and Analysis of Hardened Structures, Final Report Jun 71-May 74 (No. AD-B-004152/5), Civil Nuclear Systems Corporation, Albuquerque, NM, USA, 1974.

[6] B. M. Das, Fundamentals of Soil-Dynamics, Chapter 4, Elsevier, Amsterdam, Netherlands, 1983.

[7] H. L. Brode, A Review of Nuclear Explosion Phenomena Pertinent to Protective Construction, $R 425$ PR, The Rand Corporation, Santa Monica, CA, USA, 1964.

[8] M. S. Agbabian, Design of Structures to Resist Nuclear Weapon Effects, ASCE Manual on Engineering Practice, Vol. 42, ASCE, Reston, VA, USA, 1985.

[9] J. H. Prevost, DYNAFLOW: A Nonlinear Transient Finite Element Analysis Program, Princeton University, Princeton, NJ, USA, 1981.

[10] F. Rischbieter and K. Michelmann, Bodenwelle bei Gasexplosionen. Beitrag der induzierten Bodenwelle zur Belastung von KKW-Strukturen, Batelle-Institut, Frankfurt, Germany, 1984.

[11] K. J. Kim and S. E. Blouin, Response of Saturated Porous Nonlinear Materials to Dynamic Loadings, Applied Research Associates Inc., South Royalton, VT, USA, 1984.

[12] H. Werkle and G. Waas, "Analysis of ground motion caused by propagating air pressure waves," Soil Dynamics and Earthquake Engineering, vol. 6, no. 4, pp. 194-202, 1987.

[13] Z. Yang, "Finite element simulation of response of buried shelters to blast loadings," Finite Elements in Analysis and Design, vol. 24, no. 3, pp. 113-132, 1997.

[14] Z. Wang, H. Hao, and Y. Lu, "A three-phase soil model for simulating stress wave propagation due to blast loading," International Journal for Numerical and Analytical Methods in Geomechanics, vol. 28, no. 1, pp. 33-56, 2004.

[15] Y. Lu and Z. Wang, "Characterization of structural effects from above-ground explosion using coupled numerical simulation," Computers \& Structures, vol. 84, no. 28, pp. 1729-1742, 2006.

[16] T. Bierer and C. Bode, "A semi-analytical model in time domain for moving loads," Soil Dynamics and Earthquake Engineering, vol. 27, no. 12, pp. 1073-1081, 2007.

[17] S. D. Wilson and E. A. Sibley, "Ground displacements from air-blast loading," Journal of the Soil Mechanics and Foundations Division, vol. 88, no. 6, pp. 1-32, 1962.

[18] M. L. Baron, I. Nelson, and I. Sandler, Investigation of Air Induced Ground Shock Effect Resulting from Various Explosive Sources. Report 2, Influence of Constitutive Models on Ground Motion Predictions, Weidlinger Associates, New York, NY, USA, 1971.

[19] Z. Wang and Y. Lu, "Numerical analysis on dynamic deformation mechanism of soils under blast loading," Soil Dynamics and Earthquake Engineering, vol. 23, no. 8, pp. 705-714, 2003.

[20] S. Wang, L. Shen, F. Maggi, A. El-Zein, and G. D. Nguyen, "Uniaxial compressive behavior of partially saturated granular media under high strain rates," International Journal of Impact Engineering, vol. 102, pp. 156-168, 2017.

[21] W. R. Perret, Ground Motion Studies at High Incident Overpressure, Sandia Corporation, Albuquerque, NM, USA, 1960.

[22] UFC Manual, Structures to Resist the Effects of Accidental Explosions, US DoD, Washington, DC, USA, UFC 3-340-02, 2008.

[23] S. B. Batdorf, "Air-inducedground shock: a one-dimensional theory," in Proceedings of International Symposium on Wave Propagation and Dynamic Properties of Earth Materials,
Albuquerque, NM, USA, August 1967, G. Triandafilidis, Ed., pp. 423-432, Aerospace Corp., San Bernardino, CA, USA, 1969.

[24] S. L. Kramer, Geotechnical Earthquake Engineering, Pearson Education, Delhi, India, 1996.

[25] X. Tong and C. Tuan, "Viscoplastic cap model for soils under high strain rate loading," Journal of Geotechnical and Geoenvironmental Engineering, vol. 2, no. 206, pp. 206-214, 2007.

[26] J. An, C. Y. Tuan, B. A. Cheeseman, and G. A. Gazonas, "Simulation of soil behavior under blast loading," International Journal of Geomechanics, vol. 11, no. 4, pp. 323-334, 2011.

[27] P. Y. Hicher and J. F. Shao, Constitutive Modeling of Soils and Rocks, John Wiley \& Sons, Hoboken, NJ, USA, 2013.

[28] S. Pathak and G. V. Ramana, "Air-blast induced ground displacement,” Procedia Engineering, vol. 173, pp. 555-562, 2017.

[29] N. M. Newmark and J. D. Haltiwanger, Air Force Design Manual, Principles and Practices for Design of Hardened Structures, University of Illinois at Urbana-Champaign, Champaign, IL, USA, 1962.

[30] A. J. Hendron Jr. and H. E. Auld, "Effectof soil properties on the attenuation of airblastnduced ground motions," in Proceedings of International Symposium on Wave Propagation and Dynamic Properties of Earth Materials, Albuquerque, NM, USA, August 1967, G. Triandafilidis, Ed., pp. 29-47, University of Illinois, Urbana, IL, USA, 1969.

[31] I. Nelson and G. Y. Baladi, "Outrunning ground shock computed with different models," Journal of the Engineering Mechanics Division, vol. 103, no. 3, pp. 377-393, 1977. 


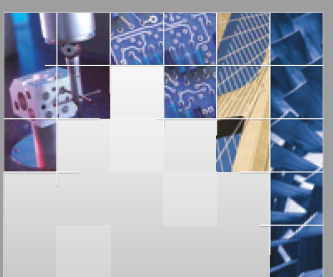

\section{Enfincering}
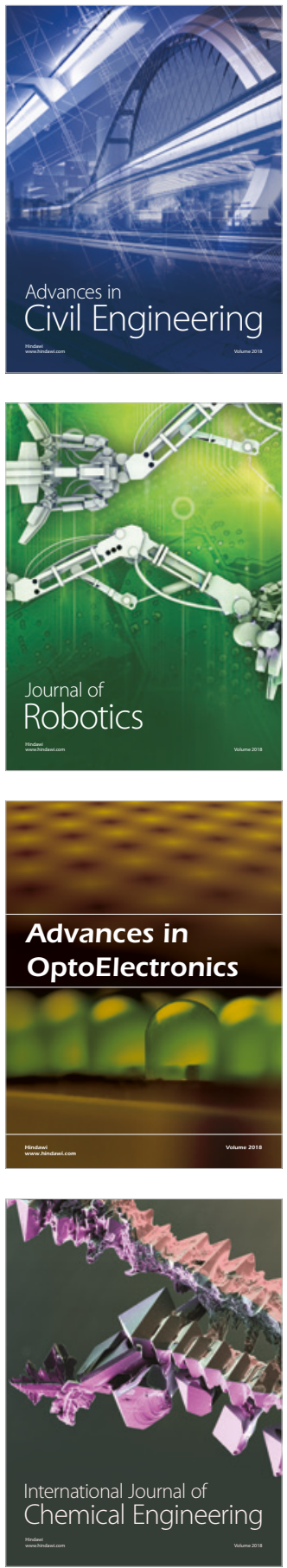

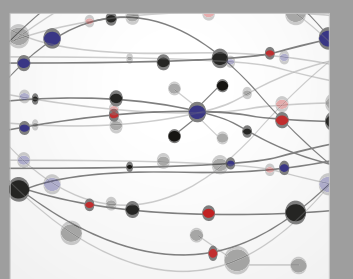

\section{Rotating \\ Machinery}

The Scientific World Journal

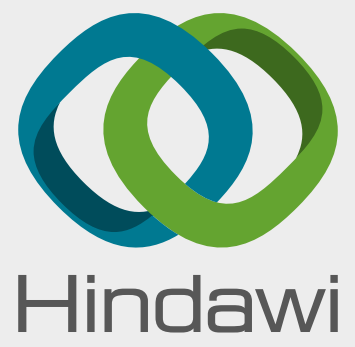

Submit your manuscripts at

www.hindawi.com
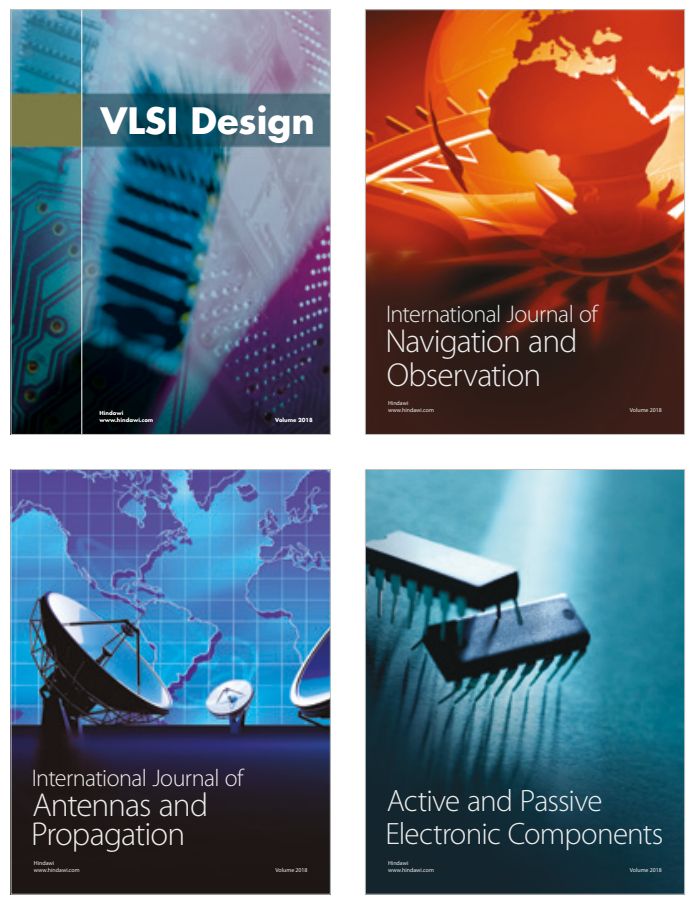
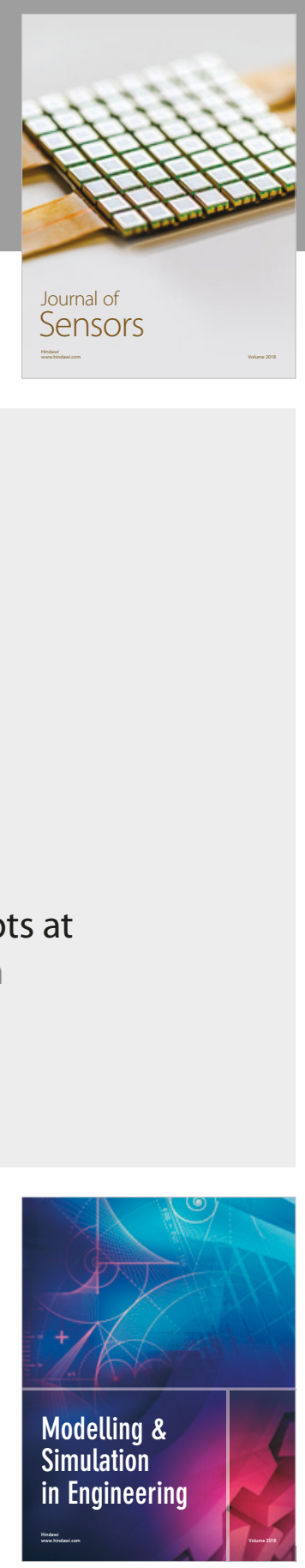

\section{Advances \\ Multimedia}
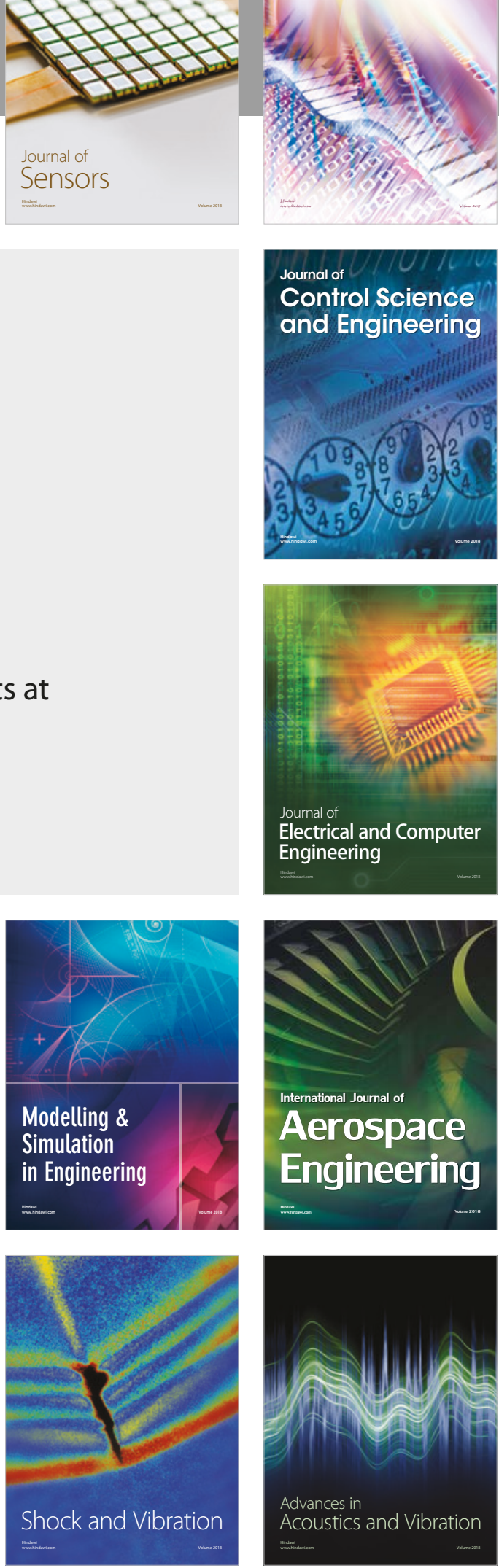